\title{
ОСОБЕННОСТИ РЕПРОДУКТИВНОГО ПОТЕНЦИАЛА И ПОКАЗАТЕЛЕЙ РАЗВИТИЯ ЭМБРИОНОВ ОТ МУЖЧИН СТАРШЕЙ ВОЗРАСТНОЙ ГРУППЫ
}

\author{
Мун Т.В., Витязева И.И. \\ ФГБУ «НМИЦ эндокринологии» Минздрава России
}

Репродуктивный период у мужчин начинается с первых поллюций и сохраняется в течение всей жизни. Вместе с тем, с увеличением возраста эта функция постепенно ухудшается. Краеугольной причиной изменений мужской фертильности служит дефицит активных форм тестостерона: резко увеличивается доля мужчин со сниженными значениями индекса свободного тестостерона - маркера биологически доступного гормона.

Падение уровней тестостерона ведет к сниженному либидо, вызывает эректильную дисфункцию и трудности в достижении эякуляции. Частота половых контактов у мужчин в 30-40 лет составляют 6,5 раз в месяц, к 50-60 годам она снижается втрое. В группе старше 40 лет около 35\% мужчин предъявляют жалобы на снижение эректильной функции и либидо. К 60 годам уже 50\% мужчин страдают эректильной дисфункцией, а до 15\% мужчин неспособны к половому акту.

Частотность сексуальных отношений в дискордантной паре является одной из причин позднего наступления беременности. Установлено 5-кратное увеличение интервала времени до наступления беременности в парах, где возраст мужчины был 45 и более лет по сравнению с 25-летними мужчинами, а возраст женщины не превышал 30 лет.

Увеличение временного интервала на достижение спонтанного наступления беременности связано и с характеристиками спермограммы возрастных мужчин. Данные литературы по этому вопросу противоречивы, но в большинстве работ отмечается снижение объема эякулята и прогрессивной подвижности сперматозоидов, увеличение фрагментации ДНК.

Изучение позднего отцовства при использовании донорских ооцитов представляет собой оптимальную модель для изучения мужского старения на репродуктивный потенциал. Коэффициенты оплодотворения и раннего дробления не показывают статистической разницы между эмбрионами мужчин до 50 и после 50 лет. Однако к 5 сутками развития эмбрионов эта разница уже просматривается. У мужчин моложе 50 лет коэффициент бластуляции в циклах с донорскими ооцитами составляет около 41\%, у мужчин старше 50 лет - около $34 \%$.

Уменьшение потенциала развития эмбриона отражается в увеличении вероятности потерь беременностей и в снижении числа родов живым плодом. Были рассчитаны риски самопроизвольного аборта для отцовского возраста 35, 40, 45 и 50 лет. Они составили соответственно 1,43, 1,58, 1,74 и 1,90. Тенденция увеличения риска прерывания беременности сохранялась даже в тех парах, когда возраст матери был меньше 30 лет.

Многочисленные эпидемиологические исследования предполагают связь между пожилым отцовским возрастом при зачатии и неблагоприятными результатами развития нервной системы у потомства, особенно в отношении повышенного риска аутизма и шизофрении.

Очевидно, что в отношении старения и фертильности мужчин остается много неизвестных. Дальнейшие исследования позволят лучше понять влияние возраста на все сферы мужской фертильности. 